\title{
Pemanfaatan Aplikasi Sistem Informasi Geografis (SIG) untuk Pemetaan SMK Kota Malang
}

\author{
Aditya Galih Sulaksono ${ }^{1}$ \\ adit@unmer.ac.id
}

\author{
Fakultas Teknologi Informasi, Universitas Merdeka Malang
}

\begin{abstract}
Malang is a very famous city because of many educational centers it has. Not only the local students who compete for seats to attend school in the city of Malang but also from various parts of the region also came to be able to take education bench in this city. SMK is one of the very new destinations also appealing to prospective students today. With the motto of SMK Bisa, such vocational schools are able to provide confidence for prospective students to compete in the world of work after graduate. To support the facilities of vocational students in Malang city, government and private institutions build some schools both public and private with the ability and excellence of each school. These schools are scattered in some strategic places. But for prospective students who have not even know the layout of vocational schools in Malang Raya, it will be quite difficult to choose various kinds of SMK in accordance with their wishes.
\end{abstract}

To facilitate prospective students to find suitable places of study in Malang, it is necessary to analyze the data of the school name, new admissions quota per year, the number of classrooms owned and the location. Then after all the data collected will be group in information by accreditation and location.

Intisari-Kota Malang merupakan kota yang sudah sangat terkenal karena banyaknya pusat-pusat pendidikan yang dimilikinya. Tidak hanya para pelajar lokal yang berebut kursi untuk bis a bersekolah dikota malang namun juga dari berbagai penjuru daerah juga datang untuk untuk dapat menempuh bangku pendidikan di kota yang berhawa sejuk ini. SMK adalah salah satu tujuan yang sangat baru juga menarik bagi para calon anak didik saat ini. Dengan motto SMK Bisa, sekolah-sekolah kejuruan seperti ini mampu memberikan keyakinan bagi para calon anak didik untuk dapat bersaing di dunia kerja selepas lulus nanti. Untuk menunjang fasilitas para pelajar SMK di kota Malang, pemerintah maupun instansi swasta membangun beberapa sekolah baik negeri maupun swasta dengan kemampuan dan keunggulan masing-masing sekolah. Sekolah-sekolah ini tersebar dibeberapa tempat yang cukup strategis. Namun bagi calon siswa yang bahkan belum pernah mengetahui tata letak sekolah SMK di Malang Raya, hal ini akan cukup kesulitan untuk memilih berbagai macam SMK yang sesuai dengan keinginan mereka.

Untuk mempermudah para calon siswa dalam mencari tempat belajar yang sesuai di kota Malang maka perlu dilakukan analisa data nama sekolah, kuota penerimaan siswa baru per tahun, jumlah ruang kelas yang dimiliki dan lokasi. Kemudian setelah semua data terkumpul akan dilakukan pengelompokan informasi menurut akreditasi dan lokasi.

Kata Kunci-Pemetaan, Sistem Informasi Geografis, SMK, Kota Malang

\section{PENDAHULUAN}

Sistem Informasi Geografis (SIG) merupakan suatu sistem informasi yang bertujuan menyajikan informasi geografis yang meliputi objek-objek yang ada di permukaan dan di dalam bumi. SIG penyajian yang disesuaikan dengan kebutuhan pengguna sistem, analisis statistik dengan menggunakan visualisasi yang khas dan mampu menyajikan analisis geografis melalui gambar-gambar peta/denah. Kemampuan tersebut membuat sistem informasi geografis berbeda dengan sistem informasi pada umumnya dan membuatnya berharga bagi perusahaan untuk memberikan penjelasan tentang suatu peristiwa, membuat peramalan kejadian, dan perencanaan strategis lainnya. [1]

Dengan menggunakan sistem informasi geografis, informasi yang ada dapat diasosiasikan pada sebuah struktur informasi yang berbasis pemetaan secara geografis, sehingga sistem informasi geografis akan memberikan peran yang besar dalam membantu mengorganisasikan informasi-informasi yang diinginkan dan akan diperoleh lebih banyak lagi informasi yang didapatkan [2][4].

Kota Malang merupakan kota dengan letak geografis pegunungan dan pemandangan indah dengan iklim yang sejuk, dan telah banyak dikenal masyarakat sebagai kota pendidikan. kotanya para pelajar. Di Kota Malang terdapat 45 sekolah SMK yang jumlahnya mencapai 45 sekolah baik Negeri maupun Swasta. Hal ini menarik minat calon siswa dengan menjadikan kota Malang sebagai destinasi bagi para calon pelajar menengah untuk menempuh pendidikan .

Untuk memberikan kemudahan para calon anak didik dalam mencari informasi tentang tempat pendidikan SMK yang tersebar di kota Malang perlu dibangun sebuah aplikasi pemetaan untuk mempermudah pencarian tempat pendidikan SMK di kota Malang. Dengan pengelompokan informasi data meliputi data nama sekolah, kuota penerimaan siswa baru per tahun, jumlah ruang kelas yang dimiliki serta letak lokasi dapat memberikan dampak positif pada sektor pendidikan di kota Malang yang bisa meningkatkan pendapatan anggaran daerah khususnya serta meningkatkan minat para calon siswa yang akan menempuh pendidikan di kota Malang.

\section{KAJIAN PUSTAKA}

\section{A. Sistem Informasi Geografis}

Sistem adalah kumpulan dari elemen-elemen yang berinteraksi untuk mencapai suatu tujuan tertentu. Informasi adalah data yang diolah menjadi bentuk yang lebih berguna dan berarti bagi yang menerimanya. Sistem Informasi Geografis (SIG) merupakan sistem infomasi berbasis komputer yang menggabungkan antara unsur peta (geografis) dan informasinya tentang peta tersebut (data atribut) yang dirancang untuk mendapatkan, mengolah, 
me manipulasi, menganalisa, memperagakan dan menampilkan data spasial (informasi bereferensi geografis) [2][3].

Sistem Informasi Geografis dapat diuraikan menjadi beberapa subsistemberikut :

1) Data Input

Subsistem ini bertugas untuk mengumpulkan dan mempersiapkan data spasial dan atribut dari berbagai sumber.

2) Data Output

Subsistem ini menampilkan atau menghasilkan keluaran seluruh atau sebagian basis data baik dalam bentuk softcopy maupun bentuk hardcopy.

3) Data Management

Subsistem ini mengorganisasi baik data spasial maupun atribut kedalam sebuah basis data sedemikian rupa sehingga mudah dipanggil, di-update, dan di-edit.

4) Data Manipulation \& Analysis

Subsistem ini menentukan informasi-informasi yang dapat dihasilkan oleh SIG. Subsistem ini juga melakukan manipulasi dan pemodelan data untuk menghasilkan informasi yang diharapkan.

\section{METODE PENELITIAN}

Metodologi yang akan digunakan dalam proses pembuatan Sistem Informasi Geografis ini adalah sebagai berikut :

1) Tahap pengumpulan data : pengumpulan data yang digunakan yaitu Studi Kepustakaan dengan mempelajari sumber-sumber pustaka yang berkaitan dengan Sistem Informasi Geografis yang akan dibangun. Data Spasial yang digunakan antara lain Peta Kota Malang dan Peta letak SMK di Kota Malang.

2) Tahap pembuatan perangkat lunak : menggunakan paradigma perangkat lunak secara waterfall, yang meliputi proses pembuatan database SMK beserta atributnya, berikutnya yaitu proses pembuatan data query untuk menunjukkan letak SMK yang dituju.

\section{A. Alur Proses Kerja}

Tahapan kerja, proses aplikasi pemetaan SMK Kota Malang dapat dilihat pada Gambar 1 berikut ini.

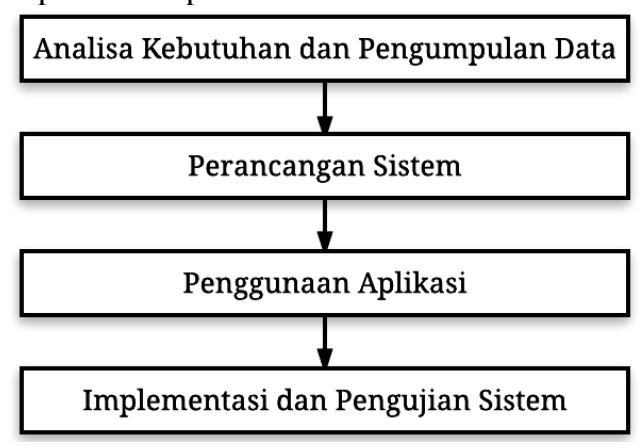

Gambar 1. Alur Kerja Aplikasi

\section{HASIL DAN PEMBAHASAN}

Aplikasi pemetaan sekolah SMK se-Malang Raya ini dibuat dengan menggunakan software Mapinfo Professional 7.5. Map Info adalah salah satu software pengolah Sistem Informasi Geografi (SIG). MapInfo diminati oleh pemakai SIG karena mempunyai karakteristik yang menarik, seperti mudah digunakan, tampilan interaktif, user frendly dan dapat dicustomized menggunakan bahasa skrip yang dimiliki. [3]
Sedangkan database dan data query yang digunakan sudah tersedia langsung didalam aplikasi, sehingga memudahkan dalam proses instalasi aplikasi pada Personal Computer (PC) dan lebih hemat resources. Berikut ini adalah hasil pembuatan aplikasi pemetaan SMK Kota Malang

\section{A. Peta Kota Malang}

Data spasial yang digunakan adalah Peta Kota Malang sebagai layer dasar dalam pembuatan aplikasi.

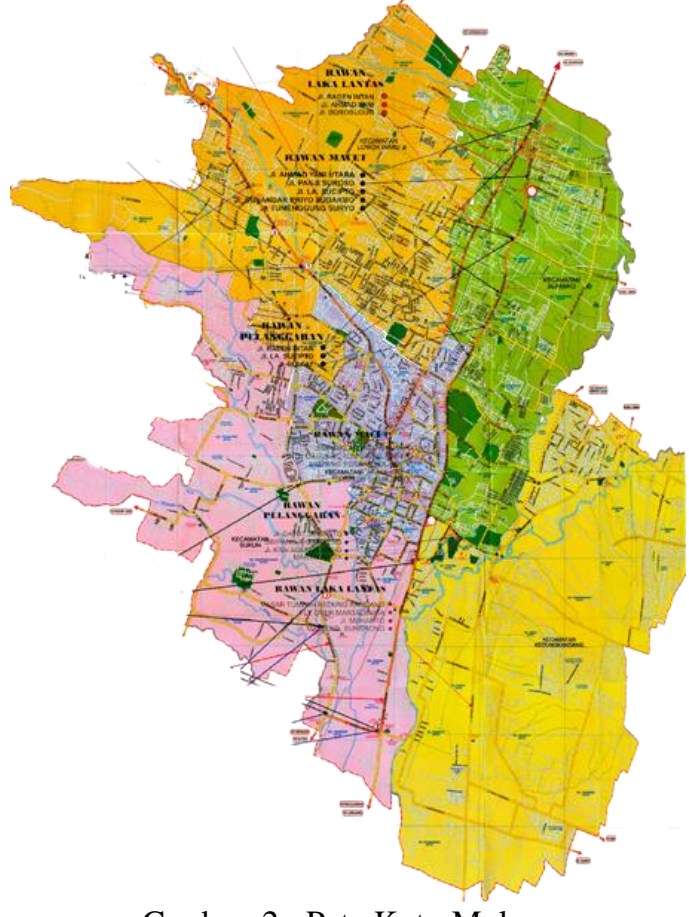

Gambar 2. Peta Kota Malang

\section{B. Data SMK Kota Malang}

Data non spasial yang digunakan adalah data SMK Kota Malang. Dengan atribut antara lain : Nama SMK, Telepon SMK, Alamat SMK, Kelurahan SMK, website SMK, ju mlah kelas SMK, kuota siswa baru, serta kelurahan letak SMK tersebut berada. Seperti yang terlihat pada struktur tabel seperti pada Gambar 2 .

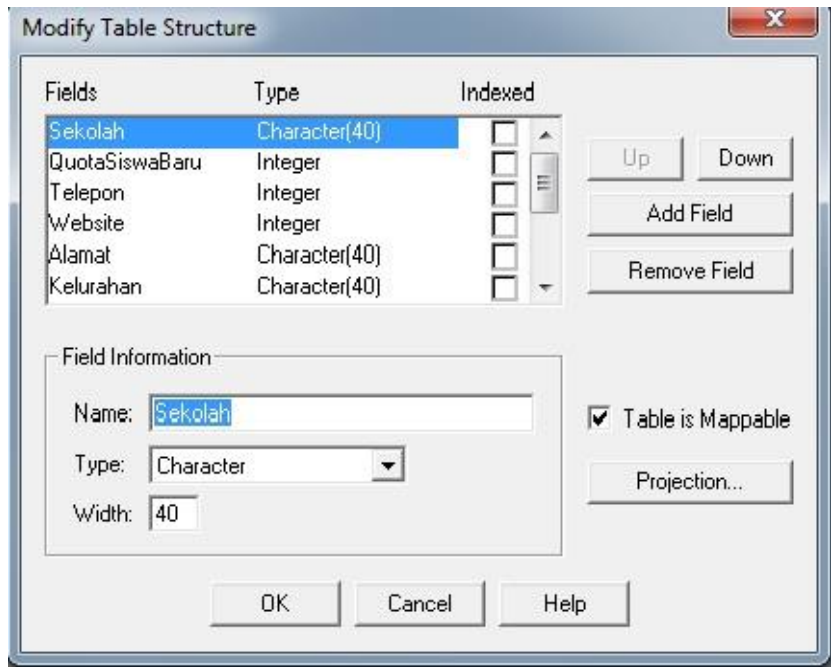

Gambar.3. Struktur Tabel SMK

\section{Pembuatan Query}


Untuk melakukan seleksi terhadap data-data pada tabel SMK diperlukan query tertentu agar mendapatkan hasil yang diinginkan. Pe mbuatan query pada MapInfo dapat dilihat pada Gambar 3.

\begin{tabular}{l}
\hline Query Table Options Window Help \\
\hline Select... \\
SQL Select... \\
Select All \\
Invert Selection \\
Unselect All \\
$\begin{array}{l}\text { Find... } \\
\text { Find Selection }\end{array}$ \\
\hline Calculate Statistics... \\
\hline
\end{tabular}

Gambar.4. Pembuatan query

\section{Pembuatan Grafik}

Data yang dibutuhkan dalam pembuatan grafik antara lain, jumlah kelas, kuota, dan sebaran SMK. Grafik tersebut menunjukkan banyaknya daya tampung ju mlah siswa terdaftar pada SMK yang bersangkutan. Contoh pembuatan grafik jumlah kelas dan daya tampung dapat dilihat pada Gambar 4, dimana atribut yang dimasukkan dalam tampilan grafik yaitu : Nama SMK, kuota SMK, jumlah kelas SMK.

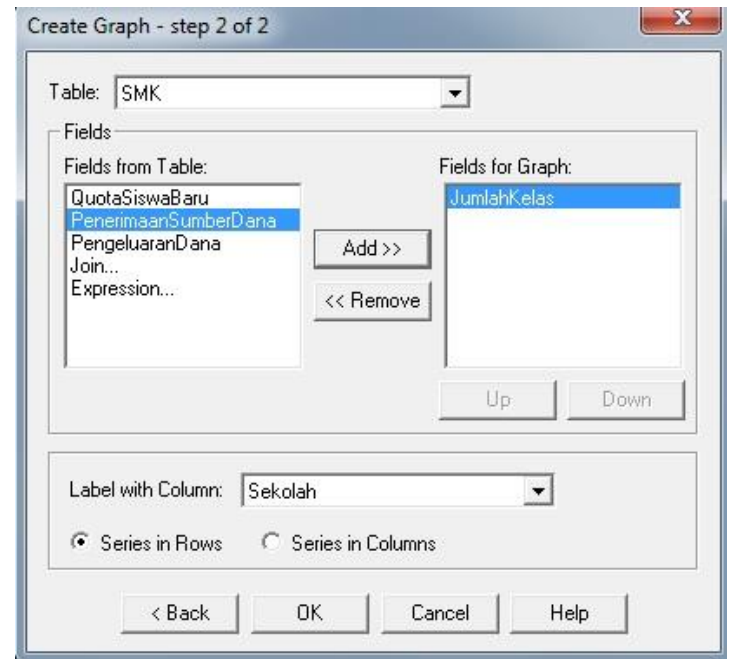

Gambar 5. Grafik Data Jumlah Kelas SMK

\section{E. Tampilan Sebaran SMK}

Pada Gambar 5 menunjukkan hasil pemetaan letak SMK se-Kota Malang yang tersebar disertai dengan nomor-nomor SMK yang terdapat di Malang sepertipada Gambar 6 .

\section{F. Tampilan Grafik SMK}

Grafik hasil pemetaan SMK se-Malang Raya menunjukkan jumlah kelas pada tiap-tiap SMK yang tersebar di Malang Raya. Seperti yang ditunjukkan pada Gambar 6 dan disertai dengan nama-nama SMK yang terdapat di Malang. Hal ini memudahkan dalam pemantauan jumlah kelas di tiap SMK seperti pada Gambar 7

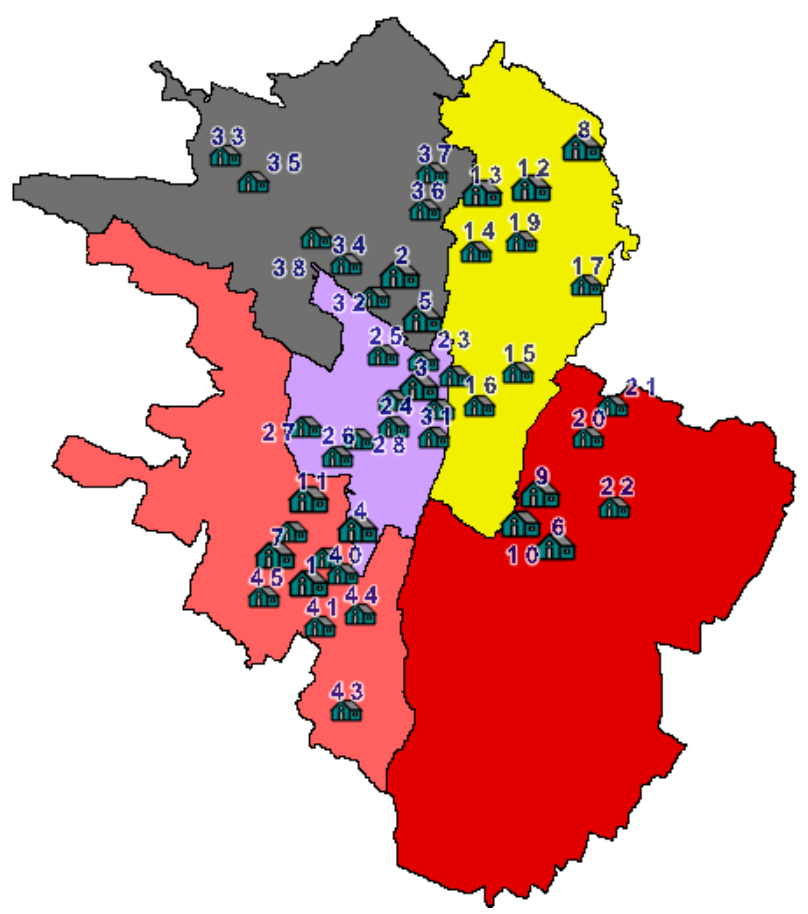

Gambar 6. Hasil pemetaan SMK se-Malang Raya

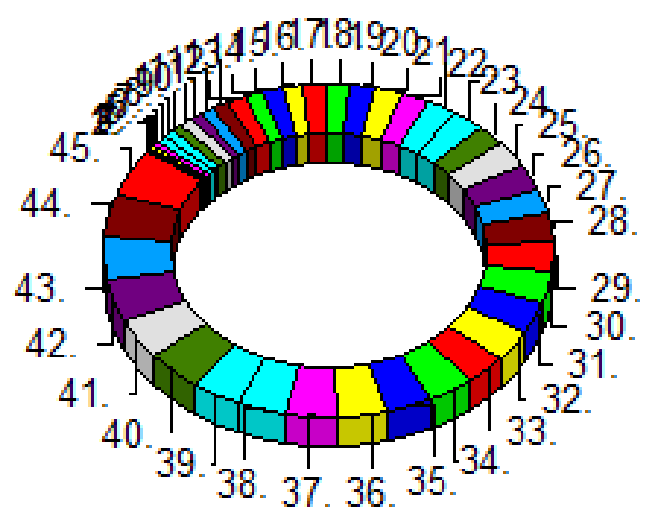

Gambar 7. Grafik Data Jumlah Kelas SMK

TABEL 1

Daftar SMK Kota Malang

\begin{tabular}{|c|l|c|c|}
\hline NO & \multicolumn{1}{|c|}{ SMK } & KUO TA & KELAS \\
\hline 1 & SMK NEGERI 01 & 720 & 46 \\
\hline 2 & SMK NEGERI 02 & 733 & 23 \\
\hline 3 & SMK NEGERI 03 & 420 & 33 \\
\hline 4 & SMK NEGERI 04 & 1130 & 76 \\
\hline 5 & SMK NEGERI 05 & 640 & 22 \\
\hline 6 & SMK NEGERI 06 & 1099 & 65 \\
\hline 7 & SMK NEGERI 07 & 164 & 12 \\
\hline 8 & SMK NEGERI 08 & 422 & 13 \\
\hline 9 & SMK NEGERI 09 & 200 & 11 \\
\hline 10 & SMK NEGERI 10 & 400 & 18 \\
\hline 11 & SMK NEGERI 11 & 320 & 12 \\
\hline 12 & SMK NEGERI 12 & 420 & 12 \\
\hline 13 & SMK ARDJUNA 2 & 105 & 9 \\
\hline
\end{tabular}

p-ISSN: 2541-6448

e-ISSN: 2541-3619 


\begin{tabular}{|c|c|c|c|}
\hline 14 & SMK KARTIKA IV-I & $\begin{array}{c}1 \\
80 \\
\end{array}$ & 14 \\
\hline 15 & SMK PRAJNAPARAMITA & 120 & 9 \\
\hline 16 & SMK PUTERA INDONESIA & 120 & 13 \\
\hline 17 & SMK PEKERJAAN UMUM & 320 & 13 \\
\hline 18 & SMK ARDJUNA 1 & 140 & 3 \\
\hline 19 & SMK TUNASBANGSA & 150 & 6 \\
\hline 20 & SMK TELKOM SANDHY PUTRA & 240 & 17 \\
\hline 21 & SMK WASKIT A DHARMA & 80 & 3 \\
\hline 22 & SMK WISNUWARDHANA & 100 & 6 \\
\hline 23 & SMK BINA BANGSA & 30 & 5 \\
\hline 24 & SMK BINA CENDIKA & 120 & 6 \\
\hline 25 & SMK COR JESU & 96 & 6 \\
\hline 26 & SMK NASIONAL & 500 & 25 \\
\hline 27 & SMK PETRA YPK JATIM & 30 & 3 \\
\hline 28 & SMK SHALAHUDDIN & 240 & 6 \\
\hline 29 & SMK SHALAHUDDIN 2 & 40 & 3 \\
\hline 30 & SMK SRIWEDARI & 60 & 2 \\
\hline 31 & SMK MUHAMADIYAH 1 & 97 & 23 \\
\hline 32 & SMK KERT A WISATA & 50 & 6 \\
\hline 33 & SMK MUHAMMADIYAH2 & 200 & 12 \\
\hline 34 & SMK MUHAMMADIYAH3 & 80 & 3 \\
\hline 35 & SMK PGRI 3 & 1000 & 0 \\
\hline 36 & SMK TARUNA BHAKTI & 80 & 4 \\
\hline 37 & SMK TUMAPEL & 120 & 5 \\
\hline 38 & SMK YP 17-2 & 80 & 3 \\
\hline 39 & SMK BHAKTILUHUR & 50 & 3 \\
\hline 40 & $\begin{array}{l}\text { SMK GRAFIKA KARYA } \\
\text { NASIONAL }\end{array}$ & 150 & 6 \\
\hline 41 & SMK PGRI 6 & 200 & 10 \\
\hline 42 & SMK PGRI 1 & 0 & 6 \\
\hline 43 & SMK YP 17-1 & 100 & 6 \\
\hline 44 & SMK PGRI 2 & 320 & 5 \\
\hline 45 & SMK NUSANT ARA & 40 & 8 \\
\hline 46 & SMK PGRI 7 SINGHASARI & 60 & 2 \\
\hline
\end{tabular}

[2] E. Prahasta, Konsep Dasar Sistem Informasi Geografis, Bandung: Informatika, 2002.

[3] E. Prahasta, Membangun Aplikasi Web-based GIS dengan MapServer., Bandung: Informatika, 2007.

[4] E. Budiyanto, Sistem Informasi Geografis Menggunakan MapInfo., Yogyakarta: Andi, 2004.

\section{KESIMPULAN DAN SARAN}

Dengan pengimplementasian program aplikasi pemetaan SMK di Kota Malang, maka diharapkan akan lebih membantu dan mempermudah para calon siswa dalam memilih SMK yang akan menjadi tempat tujuan pendidikan pada jenjang sekolah menengah yang terletak di Kota Malang Raya. Selain itu para calon siswa juga dapat melihat jumlah kelas dan jumlah kuota yang terdapat pada SMK yang akan dituju.

\section{DAFTAR PUSTAKA}

[1] J. Hariyanto, Analisis \& Desain Sistem Informasi Pendekatan Terstruktur Teori dan Praktek Aplikasi Bisnis Edisi 2, Yogyakarta: Andi, 1999. 